\title{
ESTUDO CLINICO DA PATOLOGIA AMOROSA: A EROTOMANIA
}

\section{A. CREAGH MOREIRA *}

Biologistas, moralistas, psicólogos e filósofos externaram idéias e hipóteses as mais variadas, em tôrno do velho conce.to do amor. Por isso, o estudo dos estados passionais desperta interêsse, envolvendo diferentes problemas. Apesar do estado passional amoroso resultar de múltiplos fatôres, de modo que o amor sempre aparece em função de condições diferentes, estudaremos apenas um de seus aspectos mórbidos, para limitar a assunto, dada a sua complexidade. Será estudada, especialmente, a erotomania, estado de amor crônico imaginário, em que o paciente se imagina amado ou tem a ilusão delirante de ser amado. A importância cínicica do cstudo se evidencia pela freqüente ocorrência da síndrome fora do âmbito psiquiátrico. Não raro o ps:quiatra é chamado a intervir em casos em que o delírio amoroso já se cronificou, tendo-se iniciado, muitas vêzes, em situações que justificavâm a impressão de um fato natural.

Em geral, a pessoa em quem o erotômano se fixa, tem especiais dotes morais, físicos ou intelectuais, que servem de alicerce à construção do delírio amoroso crònico. Ao lado disso, certos fatôres ambientais podem favorecer o lento desenvolvimento da síndrome. Sirvam de exemplo os casos de erotomania que se instalam nos meios hospitalares, mesmo de clínica geral, nos meios teatrais ou de rádio, quando deterninado expectador se enamora, patològicamente, pelos artistas, julgando que a vítima se acha enamorada, quando canta, ou interpretando os gestos e atitudes teatrais como sinal de correspondência em seu amor imaginário.

O erotômano não se limita, habitualmente, a viver o seu desejo imaginário, pois tenta realizá-lo, perseguindo o escolhido, sob todos os modos, escrevendo, telefonando, procurando estar junto à vítima, no trabalho, $\mathrm{em}$ casa, nas casas de amigo: ou pessoas que possam favorecer ou incentivar o delírio, o que perturba o scssêgo $e$ impede a atividade da vítima. A proporção que o objetivo se torna difícil, o erotômann se revela, em geral, mais insistente, empregando os meios mais variatos, podiendo chegar à agressão física. Por isso, a periculosidade decorrente pode ser de tal intensidade que se torna necessário a intervenção policial ou justicial, proporcionando i: vítjma os meios legais de proteção, desde a internação do erotômano em hospital espccializado, à proteção policial individual, dada a possibilidade de crime passional.

A erotomania pode apresentar-se com sintomatologia lige:ra, pouco precisa, constituinde a pequena erotomania, ao lado dos casos intensos. Quase sempre o início do delírio amoroso se faz lentamente, por via platônica. O paciente pode comecar a fixar a atenção na vítima porque essa the pareceu ser nortadora de qualidades morais, físicas ou intelectuais. Não raro, o despertar de tais sentimentos anorosos se faz sem que a vítima o perceba. Esquirol citou o caso de uma erotômana que se limitava a escrever e fazer versos a um indivíduo sem que o mesmo conhecesse à erctômana nem tivesse proporcionado motivo justificável ao desenvolvimento dos sentimentos platônicos.

Quando a síndrome erotômana se acha bem desencadeada observa-se que não existem preocupações de ordem sexual (erotismo), pois há casos de erotômanos impotentes (erotomania casta, de Júlio de Mattos). Segundo Esquirol, a erotomania se revela mais no domínio do amor-sentimento, diferente da ninfomania e satiríase, que constituem o amor-sensação, medular, que representaria a excitação sexual.

* Psiquiatra do I. A.P.C. do Distrito Federal. 
Entretanto, tratando-se de uma síndrome, admite-se a existência de casos menos puros, sobretudo no conteúdo imaginário. Existem casos descritos na literatura médica de erotomanias instaladas em pacientes que tinham vida sexual com as vítimas, pois eram casadas, amasiadas ou mesmo noivas. A fenomenologia delirante amorosa crônica e conduta patológica, marcam o conteúdo erotômano no caso ohservado. Em relação à erotomania nos homossexuais, não tivemos oportunidade de observar nenhum caso clínico.

De modo geral, Henri Claude estabeleceu o conceito de erotomania ao definir: “L'érotisme est l'exagération pathologique de l'instinct sexvel conduisant scuvent ì ries perversions de celui-ci, ou à des réactions médico-légales diverses. L'érotomanie est une déformation plûtot des sentiments amoureux, prenant un caractère passionnel, résultat d'une fixation obsèdant sur unc personne, sous la forme habituelle d'un attachement sentimental plûtot degagé de tout caractère physique".

Quanto à etiopatogenia, reconhecemos extraord nárias dificuldades em determina: a causa. A cíndrome errtômana deronde de fatôres ns comenéticns, apresentando-se com os caracteres gerais das reações r'e personalidade (Kretschmer estuda a síndrome nn canítulo das reaçñes de personalidade), quer evoluindo com aspecto de primitiva. ("délire pascional d'emblée", de Clérambault) ou aparecendo secundìriamente a certos quadros psicóticos.

Infelizmente, não encontramos, na literatura, casos de erotomania que tivessem sido psicanalicadcs. Em geral, exiśe a rreocunacãn em reparar o conteúdo psicótico da fenomenologia erotômana e. no máximo, enquadrar ou não o delírio erotômano em determinados tipns de delírio (de interpretação, de persegu ção ou de reivirdicação), deixando de ser feita a análise profunda que, certamente, seria $n$ meio de esclarecer os motivos da fivarãn do erotomano em determinados indivídurs Thé casos de erotomania. desenvolvida sem que tenha sido despertado por qualidades excepcionais das vítimas) e a estrutura do delírio amorọn crônico.

Henri Claide admite aue a síndrome se apresente na clínica sob dunlo aspecto:

1 - A erotomania pode ser a manifestação prevalente no decorrer de uma psimse nitidamente constituída. Tivemos a oportunidade de acompanhar a evolụcão de um msn nessas condicões. Tratava-se de 1.ma nacionto esquizofrênira rarranón are foi internada e cbservada nn Sanatório Rio de Janeiro onde iniciou o núcle's crotômano, que se desenvolveu ràpidamente, mesmo no decorrer do tratamento cardiazólicn. nue nãn jmnediu que n delírio erotômano se cronificasse, a ponto de tawsistir até hoje, decorridos cêrca de ano a mein, ficando como defeito esquizofrênico saliente a erotomania. A atividade delirante amornca da paciente se limitava $\therefore$ escrever e telefcnar, todos os dios, dando conta da sua vida particular. usanth expressões amorosas, tratando o ohjet:vo como noivo e. nor vêzes, considerando-o ępósn. Eis uma das inúmeras cartas escritas pela paciente, que nunca foram resnondidar pels. vítima: "Querido noivo. Tenho fé que ainda nos casaremns pelı igreja que te falei. Todas as vêzes que entro em uma, rezo 'pelo nosso amor, pec. an; céus que nos prctejam, que concretizemos nosso ideal. Querido. nense em mim; não faço outra coisa, senão penঙar em ti. Acompanhas noite e dia. ml1s penca.. mientcs, às vêzes até quando durmo. Não podemos determinar o dia de amanhã. só Deus conhece o destino do homem; porque te conheci e te amo, não sei îla saberá o resto, como fêz com que isto acontecesse, embora eu o peça em minhas preces pnrque sinto que viver sem ti, está acima de minhas fôrças. Beijos de tua noivinha".

Em bem documentado trabalho, Nelşon Pires e Mário Yahn chamam a atenção. acertadamente, para a fato de que tôda a idéia delirante de ser amado surgida em qualquer psicopata ou psiconeurótico não deve ser, a rigor, rotulada de erotomania: "A erotomania possui um terreno onde se instala, num núcleo afetivo, de onde 
parte e condiciona uma atividade particular por parte do doente, possível de ser previstis até conseqüências mínimas, o que justifica seu quadro à parte no capítulo dos ielirios amorosos". Freqüentemenie, tivemos oportunidade de observar atividades erotômanas em paralíticos gerais, epilépticos, esquizofrênicos, em pacientes com estados involucionais, com psicose maníaco-depressiva, que não chegaram a sistematização e persistência suficientes para permitir rotulagem como erotomania, que, enı geral, é muito rica em fencmenologia delirante imaginária crônica.

2 - A erotomania se desenvolve em aparência, primitivamente, e as manifestações passionais se completam, secundàriamente, com outras atividades delirantes. Henri Claude admite, aqui, dois tipos subagudos:

a) Existiria, prèviamente, uma constituição paranóica. Há casos de erotoma nia que se instalam em personalidades paranóicas e, se compulsarmos os livros de Isiquiatria, veremos que a erotcmania é estudada no capítulo da paranó a, sendo ¿̇dmitida, mesmo, a existência de uma paranóia erótica (Lichtenstein e Samall, Sadler,

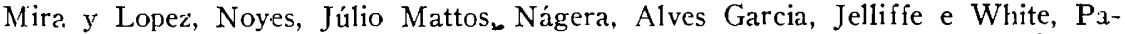
checr. c Silva). E nossível, entretanto, a existência de erotomanias não condicionadas: à constituição paranóica. Dos delírios freqüentemente encontrados na paranóia, o delírio de interpretação é considerado por Capgras e Serieux como erotômano.

Realmente, alguns casos observados deixam evidenciar, nitidamente, a interpretação delirante. Mesmo as dificuldades que os erotômanos encontram por parte da vítima levam os pacientes às interpretações delirantes mais variadas. Ainda devemos deixar assinalado que outros delírios de perseguição, reivindicação e mesmo de influência, podem ser observados nos erotômanos, coexistindo ou sucedendo.

Tivemos opcrtunidade de acompanhar o lento desenvolvimento de um caso de erctcmania, iniciado no Sanatório Rio de Janeiro, em paciente judia, idosa, cujo distúrbio se desenvolveu por simples apreciação dos dotes morais da vítima. E verdade que fatôres de desajustamento no lar, abandono moral, condição de personalidade marginal de Robert Park e preocupação de doença grave na família representaram coadjuvantes da fixação erotômana. Inicialmente, a paciente revelava os traco: essenciais das personalidades histéricas, tendo vários ataques histéricos en grande estilc, diante da resistência em entender-se com a vítima, que passou a se esquivar da erotômana, pois era prejudicada, devido aos telefonemas, cartas, presença diária no lccal de trabalho, importunação em casa e na rıa. Ulteriormente, começaram a sc tornar salientes as interpretações delirantes, atribuindo a doente as dificuldades que encontrava em avistar a vítima à interferência de terceiros (a família, a fadiga do trabalho, o cansaço devido à própria insistência, etc.) Diante dessa resistência, as man.festaçc̃es de conversão somática foram substituídas por atividades paranóicas, traduzidas por atitudes de desconfiança, exagerado egocetrismo, orgulho (freqüentemente a paciente dizia: "o que êle pensa quem sou eu? Sou muito importantr: en......, muito conhccida, procurada, com relações com pessoas da alta sociedade") e sentimento de exagerada superioridade moral, o que permitiu sal:entar-s", agora, o seu comportamento francamente paranóico sistematizado.

b) Casos em que não pré-existiria o terreno paranóico. São as formas puras estabelecidas por Clèrambault ("délire passionel d'emblée"), discutindo-se a sua existência clínica.

Em resumo, afora as erotomanias puras de Clérambault, a erotomania se apresenta, na clínica, como síndrome amorosa crònica, sobressaindo a atividadc delirante imaginária, persistente e sistematizarda, dependente de fatôres psicogenéticos, evolu:ndo em diversos tipos constitucionais (reação de personalidade), guardando, entretanto, homogeneidade de sintomatologia que permite estudo àparte, no capítulo dos delírios passionais. 


\section{BIBLIOGRAFIA}

1. Pires, N. e Yalın, M. - Erotomania. Arq. Assist. a Psicopatas de Săo Paulo, 8: 4 (março-junho) 1943.

2. Claude, H. - Psychiatrie Médico-légale. G. Doin, Paris, 1944, pág. 239.

3. Kretschmer, E. - Psicologia Médica. Trad. castelhana, Editorial Leyenda, México, 1945, pág. 380 .

4. Morselli, E. - La psicanalisi. Fratelli Bocca Editori, Milano, 3.2 edizione, 1944, pág. 238.

5. Mattos, J. - Elementos de Psiquiatria. Livraria Chradron, Porto, 1911, pág. 590.

6. Ballet, G. - Traité de Pathologie Mentale. G. Doin éditeur, Paris, 1903, pás. 573.

7. Vallejo Nágera, A. - Tratado de Psiquiatría. Salvat editores, Barcelona, 1944, pág. 551 .

8. Jelliffe, S. E. e White, W. A. - Diseases of the Nervous System Lea and Febiger, Thiladelphia, 6.a edição, 1935 , pág. 983

9. Garcia, J. A. - Compêndio de Psiquiatra. Ed. A Casa do Livro, Rio de Janeiro, 1942, pág. 281 .

10. Rabinowicz, L. - O Crime Passional. Ed. Livraria Académica, São Paulo, 1937.

11. Reik, T. - El Amor visto por un Psicólogo. Fditorial Nova, Buenos Aires, 1947.

12. Reik, T. - Psicologia de las Relaciones Sexuales, Editorial Nova, Buenos Aires, 1947

13. Ribot, T. - La Psicologia de los Sentimientos. Editorial Albatros, 1945.

14. Mira y Lopez, E. -- Cuatro gigantes del alma. El Ateneo, Buenos Aires, 1947, pág. 159

15. Bouyer, H. e Sisteron, M. - L'Hygiène Mentale et Nerveuse Individuelle. A. Maloine, Paris, 1926, pág. 255.

16. Sadler, W. S. - Modern Psychiatry. Mosby C., St. Louis, 1945, pág. 40.

Rua Real Grandeza 53, Apart. 302 (Botafogo) - Rio de Janeiro - Brasil. 